\title{
PLANO DE NEGÓCIOS DE UMA CONFECÇÃO A PARTIR DO PRODUTO: ESTUDO DE CASO EM UMA MICROEMPRESA
} MINEIRA

Talita Venilda Guimarães (talitavguimaraes@gmail.com) - Universidade Federal de Minas Gerais (UFMG)

Samyra Cecília Resende de Melo (melo_samyra@ hotmail.com) - Universidade Federal de Minas Gerais (UFMG)

Eduardo Romeiro Filho (romeiro@dep.ufmg.br) - Universidade Federal de Minas Gerais (UFMG)

\section{Resumo}

As PMEs - Pequenas e Micro Empresas são amplamente reconhecidas por sua importância econômica e social, notadamente para geração de empregos e garantia da economia local por meio do empreendedorismo. Por outro lado, a ausência de um plano de negócios adequado representa um risco para a sustentabilidade das PMEs, em especial daquelas nascentes, em processo de implantação ou (busca de) consolidação. Este artigo apresenta o processo de elaboração de um plano de negócio para implantação de uma confecção de roupas femininas, focada em calças de cós alto em Itabirito, cidade da região central de Minas Gerais. A partir de uma revisão de literatura e pesquisa de mercado, foi realizado um estudo sobre a sustentabilidade do negócio, quando foram levantadas informações junto a clientes, fornecedores e concorrentes. Ao final do estudo foi possível identificar os componentes necessários para uma elaboração do plano de negócios para a confecção, direcionando a empresa para alcance dos seus objetivos nos próximos cinco anos.

Palavras chave: MPEs; confecção; empreendimento; calças de cós alto; roupas 


\section{INTRODUÇÃ̃O}

O empreendedorismo no Brasil vem crescendo, com uma expectativa de mais de 4.660.000 MPEs - Micro e Pequenas Empresas em 2022 (SEBRAE, 2016). Dornelas (2017), mostra a importância das MPEs para o nosso país: representam 98\% das empresas existentes no Brasil; $21 \%$ do Produto Interno Bruto (PIB); 52\% do total de empregos com carteira assinada; 29,4\% das compras governamentais; 10,3 milhões de empreendedores informais; 4,1 milhões de estabelecimentos rurais familiares; $85 \%$ do total dos estabelecimentos rurais. Em todo o mundo, as PMEs representam 90\% do total de empresas existentes (COSTA; GOUVINHAS, 2005).

Estas empresas, entretanto, ainda são criadas e geridas de forma empírica e muitos empreendedores desprezam a necessidade de análise e planejamento do novo negócio que desejam empreender. Pesquisa realizada pelo Sebrae (2016) sobre os fatores de mortalidade das empresas brasileiras, indica que o planejamento do negócio é um dos principais "fatores contribuintes para a sobrevivência/mortalidade de empresas". Desta forma, é essencial fazer o plano de negócio e analisá-lo para aumentar as chances de sucesso do seu empreendimento. $\mathrm{O}$ plano de negócio pode e deve ser usado por todo e qualquer empreendedor que queira colocar em prática seus sonhos, seguindo um caminho lógico e racional, aumentando assim as chances de sucesso do seu empreendimento (DORNELAS, 2017).

Contudo, muitas empresas ao fazer uso desta ferramenta utilizam-se de textos editados sobre um modelo predeterminado, não adequando à realidade de seu empreendimento e levando ao desacerto, fazendo com que muitos pensem que o plano de negócio é ineficiente. Esta ferramenta também é muito utilizada como exigência para aprovação de empréstimos, ingresso em incubadoras de empresas ou recursos financeiros de órgãos do governo. Costumam ser elaborados exclusivamente para esses fins, às pressas, sem muito embasamento ou até mesmo com números irreais ou aproximações grosseiras.

De acordo com Maximiano (2011), o plano de negócios é uma descrição detalhada do empreendimento, de seu funcionamento e de tudo que é fundamental para sua abertura. Ele serve tanto para orientar o empreendedor, como também para dar entrada em financiamento no banco, e mostrar o potencial do novo negócio para futuros investidores. 
O plano de negócio descreve os objetivos do negócio e quais passos devem ser dados para que esses objetivos sejam alcançados, diminuindo os riscos e as incertezas. É fundamental construir o plano de negócios para concluir se o empreendimento é viável ou não, avaliando de forma estruturada os pontos fortes e fracos do negócio, os clientes, fornecedores e concorrentes. Ao final do estudo o empreendedor consegue identificar se compensa abrir ou não o novo negócio. É importante ressaltar que o plano de negócio é uma ferramenta iterativa e deve estar em contínua atualização:

Uma tradição a ser quebrada é achar que o plano de negócios, uma vez concebido, pode ser esquecido. É um erro imperdoável, e as consequências serão mostradas pelo mercado, em constante mutação. A concorrência muda, o mercado muda, as pessoas mudam. E o plano de negócios, como ferramenta de planejamento que trata essencialmente de pessoas, oportunidades, contexto e mercado, riscos e retornos, também muda." (DORNELAS, 2017, p. 94).

A análise de mercado é uma das principais etapas do plano de negócio, é a partir dela que o empreendedor fica por dentro das variáveis de mercado e não se baseia apenas nas suas suposições, sendo constituída sobre três pilares: clientes, fornecedores e concorrentes. Albrecht (1992) conceitua o cliente como sendo um indivíduo que tem necessidades e preocupações, e menciona que o cliente, sempre deve estar em primeiro lugar, mesmo que não tenha motivo. Desta forma, a empresa tende a se sobressair pela qualidade do serviço. Para facilitar a identificação das características que abrange a análise dos clientes, Rosa (2013) três passos descritos na Tabela 1. 
FIGURA 1 - Análise de Mercado - Estudo dos Clientes

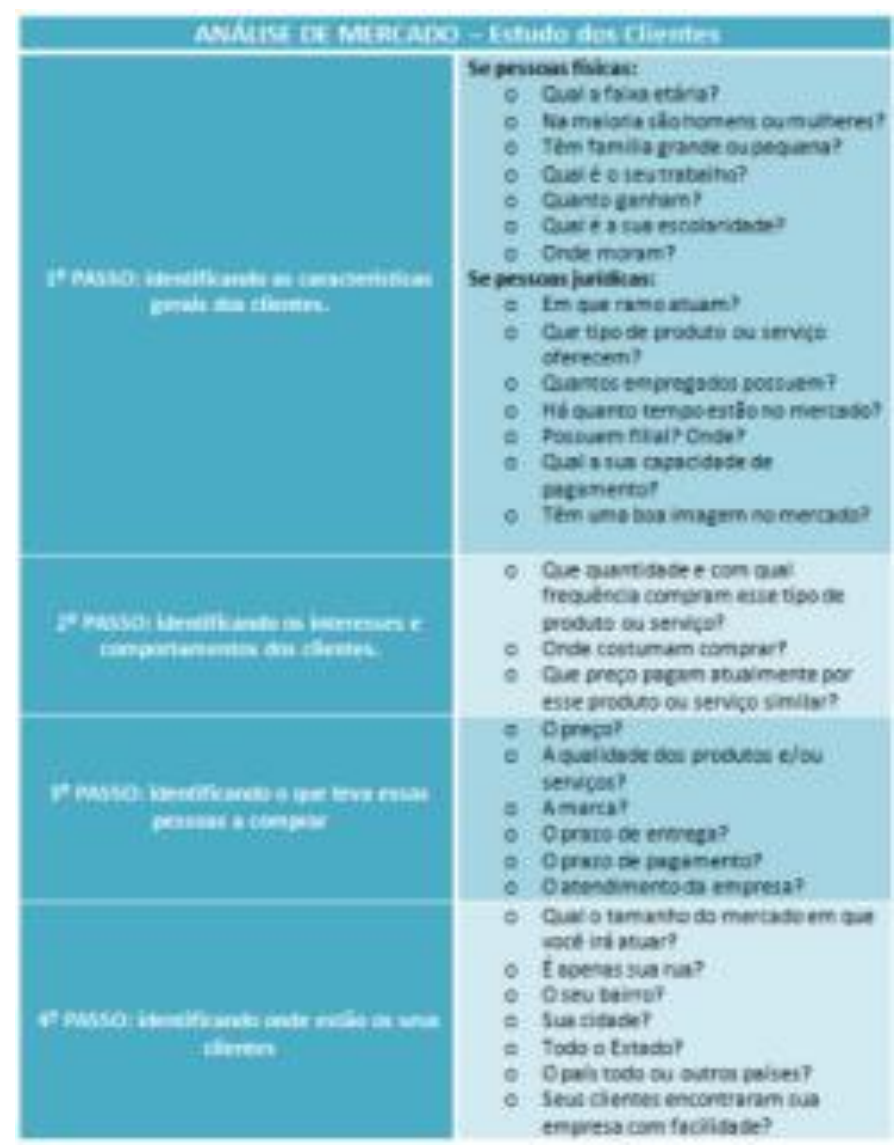

Fonte: Rosa (2013)

O cliente é naturalmente o foco principal do plano de marketing (LONGENECKER, 2011), mas este deve também conter um estudo consistente da concorrência. Dessa maneira é possível apresentar estratégias, e criar o plano de ação que transforma o produto ou negócio, observando as necessidades dos consumidores. É fundamental apresentar no plano de marketing a análise de mercado (cliente, fornecedor, concorrente), o estudo dos produtos ou serviços, a estratégia empresarial, as estratégias de marketing e a projeção de vendas. Lacruz (2008) descreve o plano de marketing como sendo a conexão entre o empreendimento e o cliente. Visto que é a partir da construção do plano que se estabelecem as estratégias com a 
finalidade de convencer os potenciais clientes a obterem o seu produto ou serviço do seu negócio, ao invés dos disponibilizados pelos seus concorrentes. O plano de marketing pode ser dividido em cinco seções: descrição dos principais produtos e serviços; preço; estratégias promocionais; estrutura de comercialização; localização do negócio (ROSA, 2013).

De forma análoga, o planejamento estratégico é um apoio para decisões das empresas. Abosede, Obasan e Alesse (2016) reforçam que as empresas com estratégia consolidada podem se diferenciar das demais e que a Análise de Mercado permite um entendimento do ambiente onde a empresa está inserida. Para esse objetivo, o empreendedor pode utilizar o plano de negócios para aumentar o sucesso e minimizar os erros, sendo possível fazer uma organização das ideias e obter conhecimento de diversas áreas da empresa e tomar diversas decisões de estratégia quanto ao rumo da organização.

Um plano de negócio é um documento que escreve por escrito os objetivos de um negócio e quais passos devem ser dados para que esses objetivos sejam alcançados, diminuindo os riscos e as incertezas. Um plano de negócio permite identificar e restringir seus erros no papel, ao invés de cometê-los no mercado.” (ROSA, 2013, p.8)

Sendo assim, o objetivo do presente estudo é analisar a viabilidade da abertura de uma confecção de roupas femininas com foco no produto, ou seja, em modelos de calças de cós alto, localizada na cidade de Itabirito, na região central de Minas Gerais. Por meio de pesquisas de mercado e elaboração de um plano de negócio, foi possível analisar a aceitação do público-alvo ao produto principal da empresa, verificar a viabilidade financeira do novo empreendimento e o perfil dos consumidores finais.

\section{METODOLOGIA}

Foi realizado um estudo de caso (YIN, 2001), com elementos de pesquisa-ação (THIOLLENT, 1985, 2007) em uma pequena confecção, em processo de preparação para abertura. Foi visitado o local da (na época) futura empresa e levantadas informações a respeito do propósito (objetivo, público-alvo e produtos que seriam desenvolvidos) e o processo de estruturação da empresa. Para isso, foram realizadas entrevistas com as proprietárias da confecção (a mãe, que já possuiu uma confecção e a filha, nova empreendedora). 
Foi também realizada coleta de dados no site da Associação Brasileira de Vestuário, Portal do Sebrae - Serviço Brasileiro de Apoio às Micro e Pequenas Empresas, do Ministério da Economia e IBGE - Instituto Brasileiro de Geografia e Estatística.

Utilizou-se pesquisa documental em informações levantadas junto a órgãos governamentais para obter informações socioeconômicas sobre a região onde seria instalada a empresa. Para o estudo de caso, foram realizadas coletas de dados através da aplicação de questionários para análise do comportamento (1) das consumidoras (mulheres que adquirem roupas em lojas multimarcas) e para (2) a administração de lojas de varejo, que são os clientes diretos da confecção. O primeiro questionário foi disponibilizado durante dez dias pela plataforma Google Form e um total 236 mulheres, com faixa etária de 22 a 76 anos, responderam os questionários de 10 perguntas. O segundo questionário (realizado também pela plataforma Google Forms) contém 12 questões e foi aplicado em 43 lojas multimarcas localizadas em Belo Horizonte, Nova Lima, Ouro Preto, Itabirito e Mariana. Antes do envio do questionário, foi realizado contato por telefone com as empresas informando sobre o estudo.

Para o estudo dos concorrentes, foram analisadas duas confecções de moda feminina e o contato se deu através de e-mail e telefone, além de pesquisa pela internet e visitas a lojas. Após o término da coleta de dados, foram realizadas diversas reuniões para análises e idealização do Plano de Negócios, incluindo os autores deste trabalho e as empreendedoras, em uma abordagem que possui elementos de pesquisa-ação (THIOLLENT, 1985, 2007). Foram gerados tabelas e gráficos a partir da pesquisa de mercado que possibilitam análises aprofundadas, visualizando se há ou não demanda de calças de cós alto dentro da população estudada. Apenas através do estudo final desses dados foi possível compreender se os objetivos da empresa estavam claramente definidos. 


\section{RESULTADOS E DISCUSSÃO}

\subsection{A empresa}

O estudo teve o propósito de analisar a viabilidade e subsidiar a criação de um plano de negócio para a criação de uma confecção de roupas femininas a partir da perspectiva do produto, com a produção centrada em calças de cós alto, consideradas um nicho bastante específico, mas promissor (conforme a pesquisa acabou por demonstrar). O propósito da empresa é suprir a carência de modelos de calças com o cós alto na região da capital mineira. A confecção se localiza em Itabirito/MG (a $60 \mathrm{~km}$ de Belo Horizonte e 44Km de Ouro Preto) e atende, em princípio, lojas multimarcas de Itabirito, Ouro Preto, Mariana, Nova Lima e Belo Horizonte. A pesquisa realizada com lojas varejistas da região de atuação da empresa e com consumidoras finais possibilitou verificar a aceitabilidade dos produtos disponibilizados pela confecção. Dessa forma, o estudo aqui proposto buscou eliminar os riscos através de questionamentos quanto a todas as oportunidades de agregar valor e venda aos produtos. A seguir a figura 2 apresenta um organograma da empresa, incluindo terceirizados (em linha pontilhada).

FIGURA 2 - Organograma da empresa

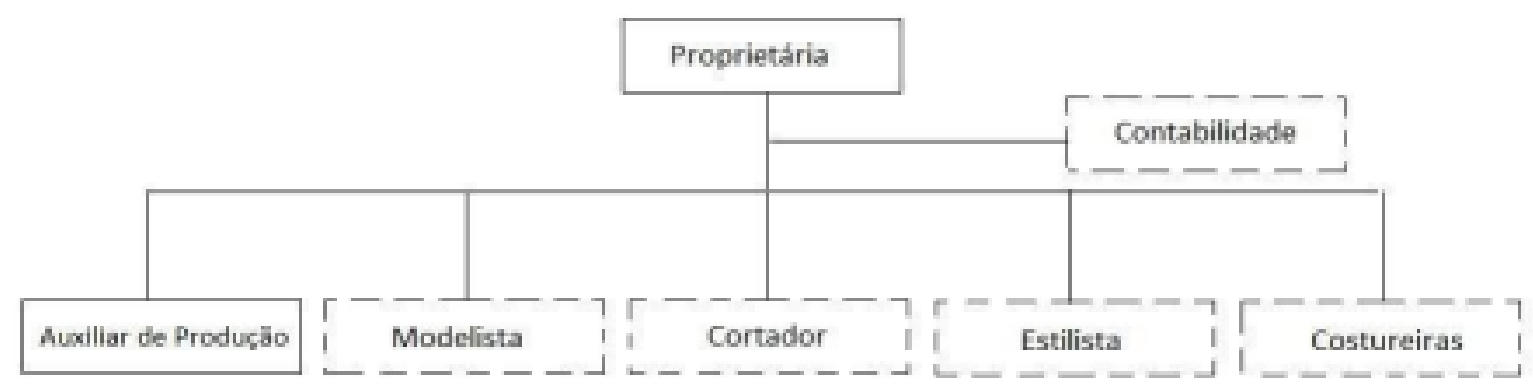

. Fonte: Elaborado pelos autores 


\subsection{O produto}

A linha de produtos da empresa inclui, além das calças de cós alto (seu carro-chefe), blusas, vestidos, casacos, saias, shorts e macacões. Para identificar e analisar os consumidores finais, e a partir de então levantar dados sobre as características dos produtos que a confecção poderá ofertar, utilizou-se dos resultados dos questionários aplicados. Foram consideradas as respostas de 136 mulheres. A primeira pergunta do questionário procurou identificar a faixa etária das entrevistadas, que oscilou entre 22 a 76 anos. Logo após as perguntas foram para a análise de mercado e características relacionadas aos produtos. Um dos questionamentos em relação aos produtos foi sobre o tamanho da roupa que as entrevistadas costumam vestir. $\mathrm{E}$ analisou-se que não há uma discrepância em quais tamanhos vendem mais. Outro fator importante que foi visualizado no gráfico é o percentual de tamanho "Plus Size". Como esse segmento tem o objetivo de tirar do consumidor a impressão de que não é possível encontrar peças do seu tamanho que sigam a tendência da moda, a confecção poderá investir em expandir as numerações ofertadas, produzindo um mesmo modelo em diferentes tamanhos. Dessa forma, um diferencial da marca será a confecção das peças em sete tamanhos: P, M, G, GG, G1, G2, G3.

Em estudo sobre a moda "Plus Size", a Associação Brasileira de Vestuário (Abravest) analisou que em 2018 esse mercado cresceu 6\% no ano e movimentou aproximadamente 5 bilhões de reais no país. E a expectativa é de um crescimento ainda maior, de pelo menos $10 \%$ ao ano. No gráfico 1, encontram-se os dados obtidos com a pesquisa ao consumidor final. 
GRÁFICO 1- Qual tamanho de roupa você veste?

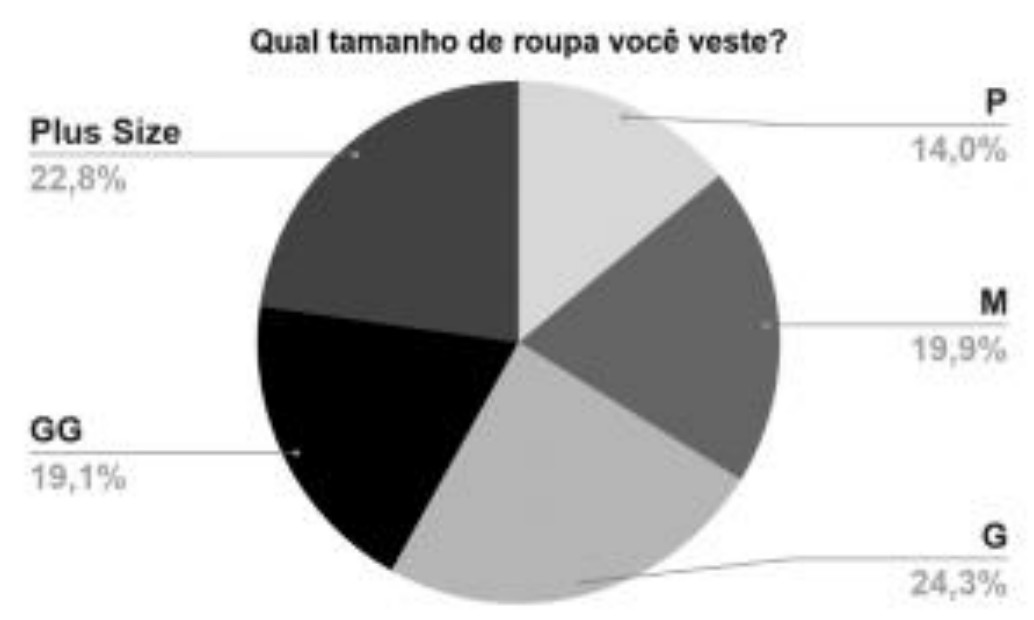

Fonte: Elaborado pelos autores.

Outra questão levantada foi associada aos atributos que são levados em consideração ao comprar uma roupa. Dentre cinco opções que as autoras apresentaram, as entrevistadas foram convidadas a escolherem uma ou duas que para elas são mais relevantes. Ao analisar o gráfico 2 com os dados recolhidos, a alternativa que mais destoou foi "Marca". Ou seja, a maioria das entrevistadas não considera a marca da roupa ao fazer uma compra. De outro

lado, as duas peculiaridades que são consideradas ao comprar uma peça de roupas, de acordo com a pesquisa, são: a praticidade ao lavar/passar e o preço. 
GRÁFICO 2: Quais atributos você considera ao comprar uma roupa?

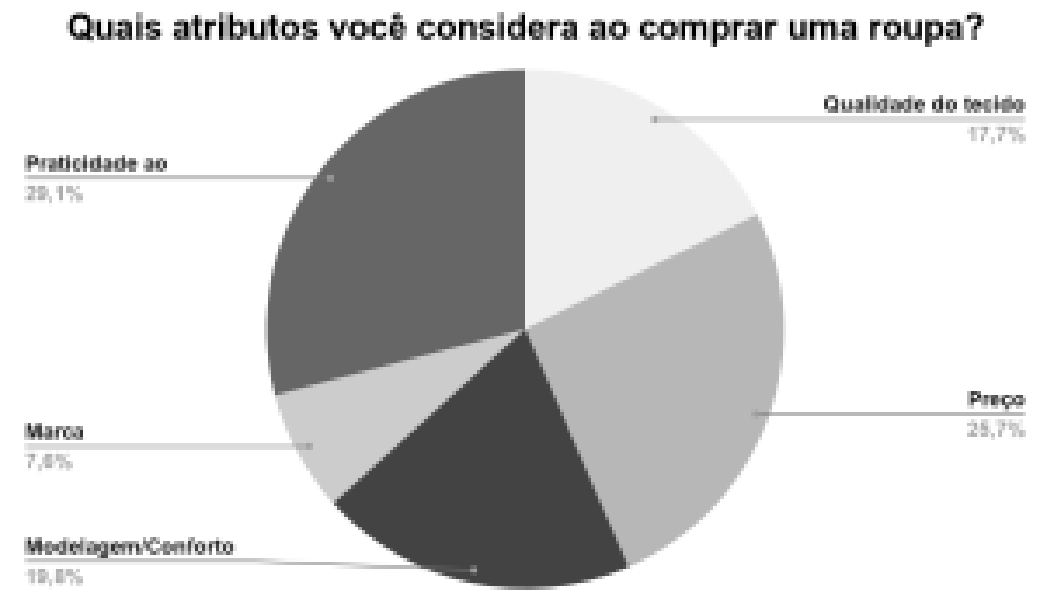

Fonte: Elaborado pelas autoras.

Como o foco da confecção é a venda de modelos de calças com cós alto, incluímos no questionário sobre a preferência das entrevistadas em relação a modelagem das calças, para fazer a validação. Para uma melhor compreensão, foi disposto no questionário a figura abaixo:

FIGURA 3: Modelagens de calças

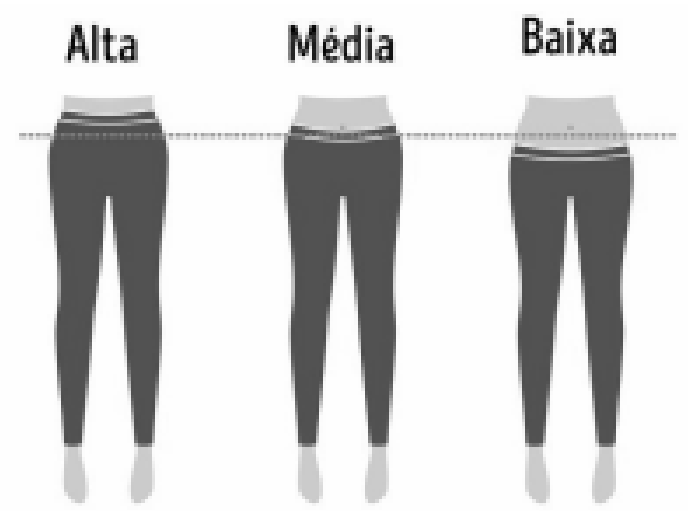

Fonte: Google Imagens 
GRÁFICO 3: Qual você prefere utilizar: calça de cós alto, cós médio ou cós baixo?

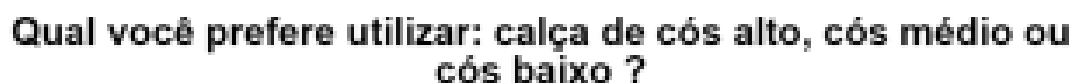

\section{cós baixo?}

so

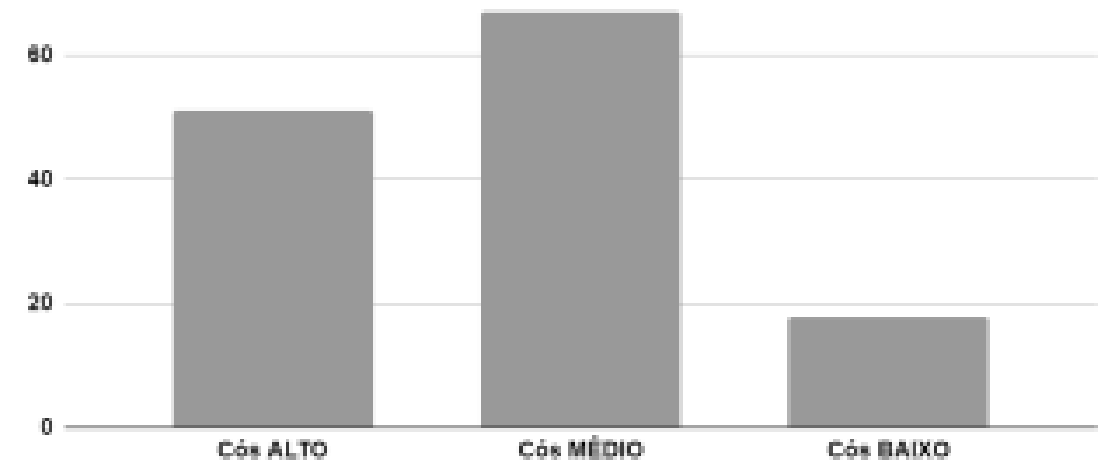

Fonte: Elaborado pelos autores.

Como expressado no gráfico acima, a preferência das entrevistadas está nas calças de cós médio, seguido de calças de cós alto. Cerca de $13 \%$ das mulheres que responderam nosso questionário tem preferência por calças de cós baixo, mostrando assim uma certa aversão do mercado em relação a esse produto. Apesar das calças de cós médio terem alcançado uma maior preferência na pesquisa, a modelagem de cós alto também obteve um nível alto de aceitação no mercado, com $40 \%$. Elencando essa informação com a pergunta subsequente sobre a oferta 


\section{Qual o nível de dificuldade para encontrar calças de cós alto no mercado?}

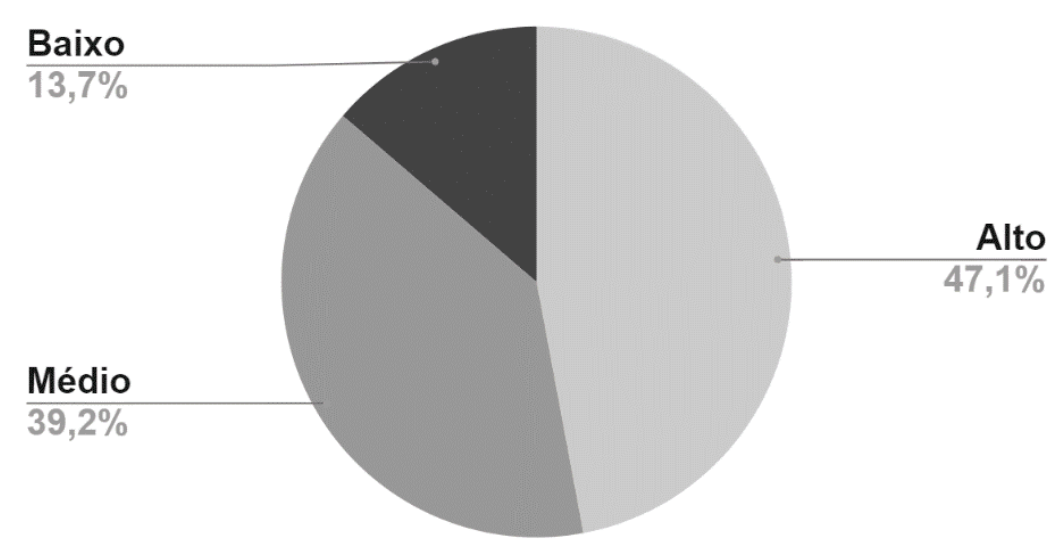

GRÁFICO 4: Qual o nível de dificuldade para encontrar calças de cós alto no mercado? FONTE: Elaborado pelas autoras.

desse modelo no mercado foi possível concluir que há pouca oferta deste produto no mercado, indicando uma boa oportunidade de produto.

\subsection{Fast Fashion}

A confecção em estudo pretende implementar um modelo de projeto e produção "fast fashion" como descrito por Ferreira e Romeiro, 2019, que oferece flexibilidade na produção e uma comunicação ágil das lojas com a confecção. Essa comunicação auxilia a empresa a rapidamente fabricar os produtos que tiveram maior saída nas lojas e, de modo oposto, retirar os modelos que não venderam, reduzindo desse modo os estoques e os produtos devolvidos. Esse modelo busca diminuir as incertezas de demanda e de modo conjunto incrementar as vendas, desenvolvendo produtos de ciclo de vida curto.

O desenvolvimento de um novo produto em uma confecção (especialmente de pequeno porte) se inicia com o estudo das tendências e matérias primas que estão "em alta" para a estação em que a peça será comercializada. Para tal, busca-se inspiração em feiras de moda, como por exemplo: Minas Trend (Belo Horizonte), FENIN Fashion (São Paulo), São Paulo Fashion Week, Fashion Rio (Rio de Janeiro). 
Também em sites de moda, revistas especializadas para estilistas, novelas brasileiras (de televisão) e no aplicativo Instagram (atualmente esse aplicativo tem sido uma ótima ferramenta de inspiração e também de pesquisa de tendências e consumo de moda).

No caso do fast fashion, há uma redução no tempo dessas pesquisas de tendências e um direcionamento mais focado nas pesquisas de consumo. Observa-se o que os consumidores realmente estão comprando para, em seguida, começar o processo de "criação" e produção de roupas. As confecções que são criadoras de moda não vêem com bons olhos o modelo fast fashion, uma vez que a maior parte das empresas confeccionam roupas similares àquelas que foram desenvolvidas por estilistas e marcas renomadas, acelerando um processo de cópia comum na indústria da moda (LOPES, 2019). Os clientes, em sua maioria, se atentam mais ao estilo e preço dos produtos do que aos "bastidores" das empresas de moda. (DELGADO, 2008). O objetivo da empresa é criar produtos com apelo às novidades mais recentes da moda, gozando de um sistema de desenvolvimento de produtos e processos de produção ágeis, a fim de abastecer rapidamente o mercado consumidor com a mínima geração de estoque. Abaixo (figura 3) o fluxograma de desenvolvimento de produto da empresa:

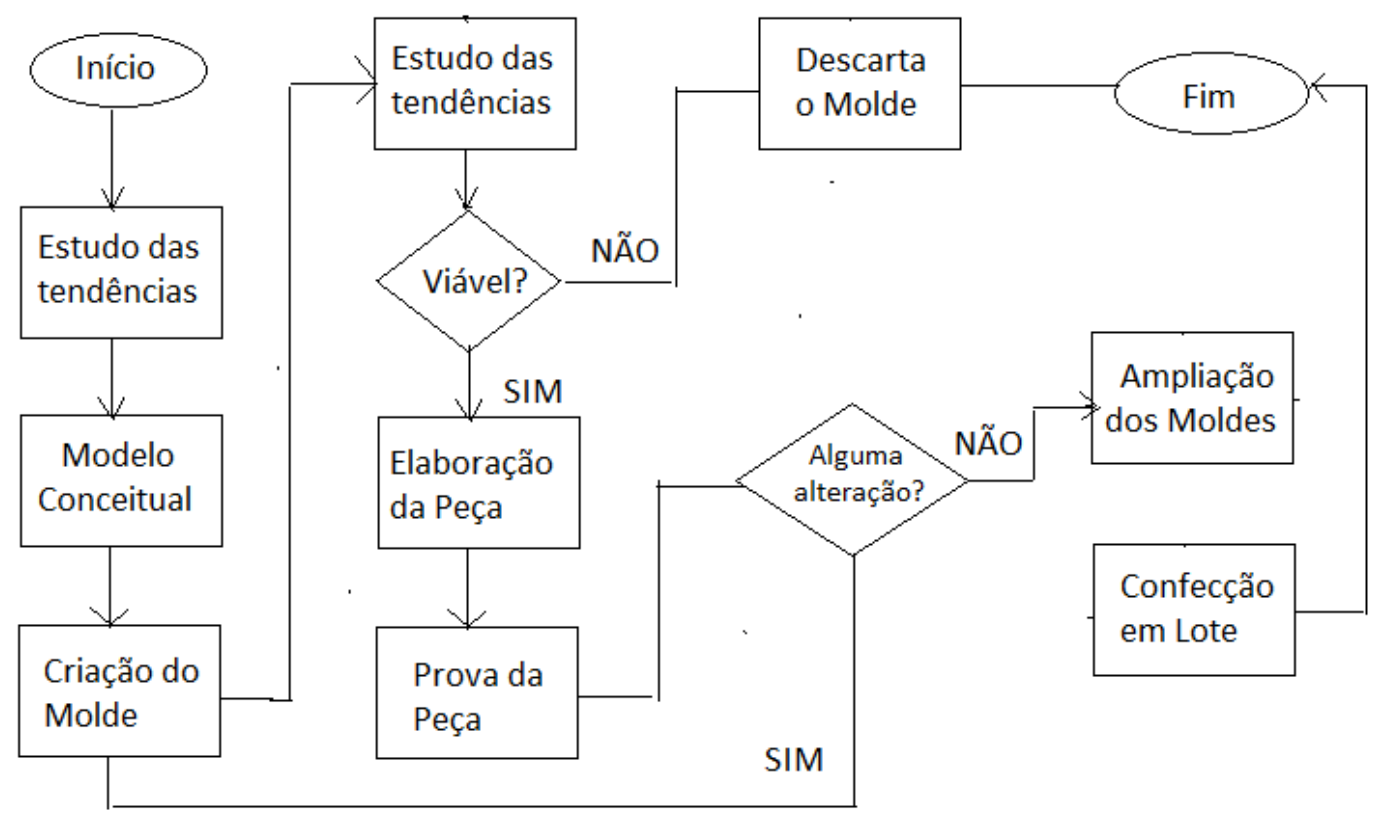

FIGURA 4 - Fluxograma de desenvolvimento de produtos. Fonte: Elaborado pelos autores. 
Após a análise das tendências e das pesquisas de consumo para compreender quais modelos e matérias primas estão sendo mais consumidas no mercado, a estilista "cria" um modelo conceitual, que é repassado para o modelista por meio de desenho, ou então são mostradas imagens ou peças de roupas já prontas (nesse caso são explicadas quais as alterações serão necessárias fazer para que chegue no modelo conceitual definido). É importante que os novos produtos tenham uma identidade da marca e atenda ao público-alvo.

Com as explicações, o modelista auxiliado com um molde base realiza a criação do molde para o novo modelo, cujo tamanho da primeira peça é definido em função da pessoa que experimentará a peça piloto (para análise do resultado e verificação da modelagem). De posse dos moldes, é calculado o custo das peças e, se for viável a fabricação, é realizado o corte, separação dos aviamentos e confecção da peça piloto. Após a pilotagem ficar pronta, é realizada a prova e observa-se se é necessário algum ajuste na modelagem ou alguma alteração no modelo. Caso seja preciso fazer alguma mudança é criado um novo molde e também é feita mais uma peça piloto. Quando não houver mais alterações para se fazer e a peça for aprovada, o modelista então faz a ampliação dos moldes para todos os tamanhos e é iniciado a produção em lote. No caso em que o custo da peça for inviável para a empresa, os moldes são descartados, para que não haja confusão com os demais moldes existentes na confecção. Para realizar esse processo de desenvolvimento de produto, é necessário que a estilista e o modelista estejam presentes na confecção, e em um dia de serviço desses profissionais consegue-se produzir em média 5 a 8 modelos novos.

\subsection{Análise de Mercado}

Foi realizada uma análise de mercado para obtenção de informações para o plano de negócio da confecção, bem como os fatores que podem impactar no sucesso ou fracasso desse empreendimento. Analisou-se o público-alvo, a relação do produto com os fornecedores e o posicionamento da concorrência. Como as vendas se darão no atacado, os clientes serão lojas de vestuário multimarcas. Para especificar quais tipos de lojas serão os clientes-alvo, utilizouse o questionário para perguntar sobre o tipo de loja que as entrevistadas compram com mais frequência, e quase $50 \%$ responderam lojas de rua. 
Qual tipo de loja você compra com mais frequência?

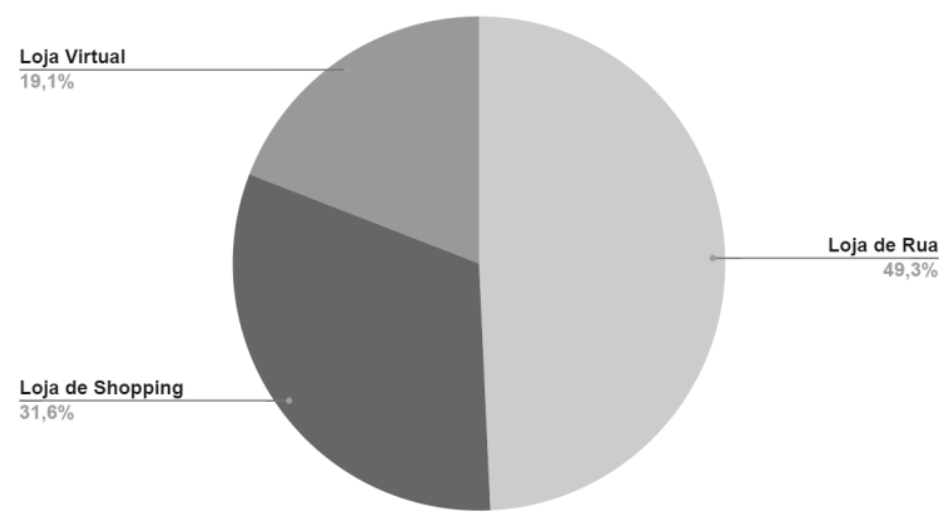

GRÁFICO 5: Qual tipo de loja você compra com mais frequência? Fonte: Elaborado pelas autoras.

A preferência por lojas de rua pode ser associada aos altos custos de ocupação das lojas em shopping (muitas vezes estas lojas não conseguem praticar o mesmo preço das lojas de rua). Em uma pesquisa atual da GS\&BGH Real Estate, empresa de consultoria para expansão de lojas varejistas, os pequenos e médios lojistas de shoppings centers destinam, em média, de $15 \%$ a $20 \%$ do faturamento mensal para cobrir custos com aluguel, condomínio e fundo de promoção. A faixa etária das entrevistadas que expressaram ter predileção por calças de cós alto foi outro aspecto relevante observado nos questionários. Elaborou-se o gráfico 4 calculando a porcentagem de mulheres de cada faixa etária que possui preferência por calça de cós alto. 


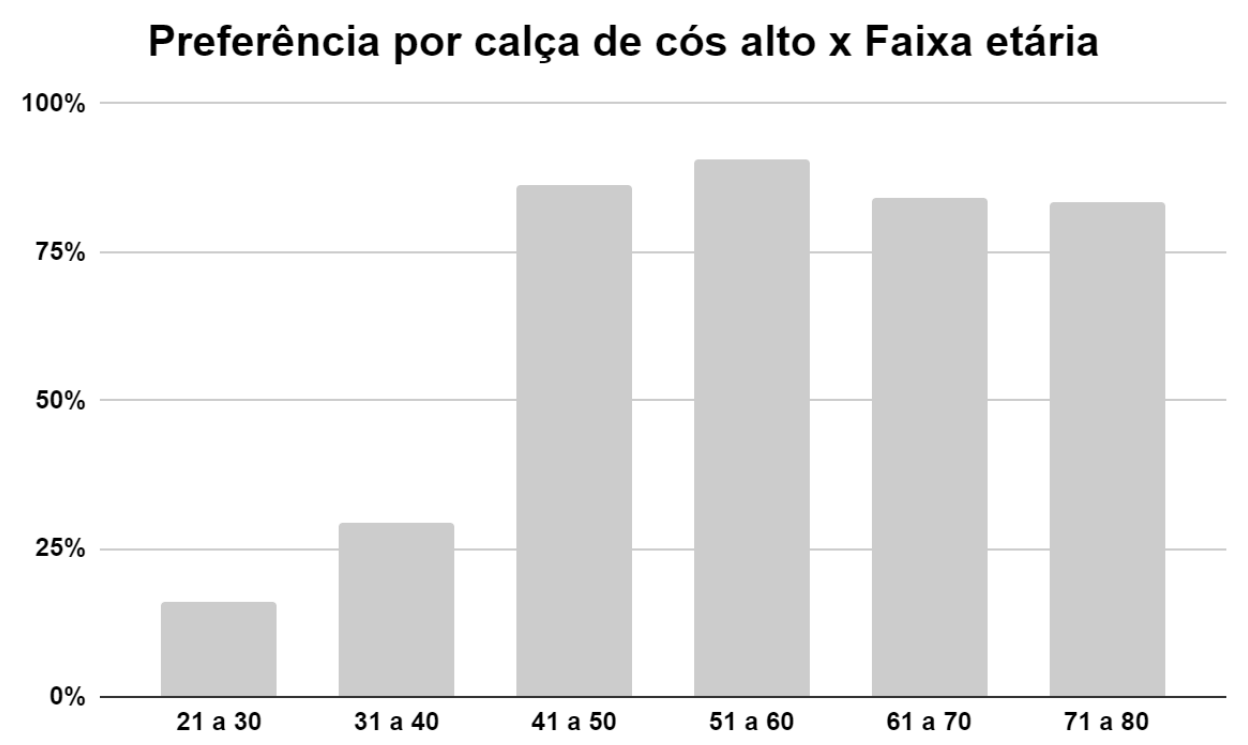

GRÁFICO 6: Preferência por calça de cós alto por faixa etária Fonte: Elaborado pelas autoras.

Em busca de maior aceitação e venda dos produtos da empresa, é viável focar em lojas de varejo voltadas para mulheres acima dos 40 anos. Dado que são as consumidoras que possuem maior preferência a esse modelo de calças. No princípio, a localização das lojas multimarcas que a confecção objetiva como clientes, são as próximas a Itabirito e Belo Horizonte devido a logística. Posteriormente a empresa pretende contratar uma empresa de transporte e o mercado será expandido para outras regiões.

Considera-se que a vantagem competitiva da empresa decorre de um portfólio com variedade em calças de cós alto. Enquanto a concorrência analisada trabalha com $20 \%$ a $40 \%$ dos modelos sendo de cós alto, a empresa em estudo busca trabalhar com no mínimo 80\%, e o restante com calças de cós médio. Esta estratégia foi vislumbrada a partir da grande demanda por esse modelo de vestuário no mercado, seguido pela carência existente. Outro ponto que será focado é na produção de um mesmo modelo em diversos tamanhos, incluindo as numerações Plus Size. A grande maioria das marcas de roupas brasileiras que atendem ao mercado Plus Size trabalham somente com esse segmento. 


\section{CONCLUSÃO}

O empreendedorismo contribui e muito para o crescimento do país, criando oportunidades de geração de renda, empregos, arrecadação de impostos, e principalmente na criação de valor agregado aos produtos. A abertura de uma nova empresa busca desenvolver novos produtos e serviços, oferecendo aos consumidores um aumento na diversidade de opções para as demandas do mercado.

O objetivo do presente estudo foi a geração de subsídios a um plano de negócios visando viabilizar a criação de uma confecção de roupas femininas focada em aspectos do produto, ou seja, calças de cós alto. Depois de apresentar todos os dados através do Plano de Negócio, as análises de mercado, marketing e operacional e financeira (estas duas últimas não apresentadas neste artigo), foi possível proporcionar o direcionamento necessário para a tomada de decisões pelas empreendedoras. A conclusão geral é que existe a viabilidade para abertura da empresa com foco no produto e sua demanda no mercado, desse modo atingindo os objetivos da pesquisa e da própria empresa.

\section{REFERÊNCIAS}

ABOSEDE, A. J.; OBASAN, K. A.; ALESE, O. J. Strategic management and small and medium enterprises (SMEs) development: a review of literature. International Review of Management and Business Research, v. 5, n. 1, p. 315-335, 2016.

ALBRECHT, K.; BRADFORD, L. J. Serviços com qualidade: a vantagem competitiva. São Paulo: Mahon Books, 1992.

COSTA, E. C. C.; GOUVINHAS, R. P. A View of knowledge management in the design department of a brazilian SME Company. Product, v. 3, n. 1, p. 99-103, 2005

DELGADO, D. Fast fashion: estratégia para conquista do mercado globalizado. Moda Palavra, ano 1, n.2, p.3$10,2008$.

DORNELAS, J. C. A. Empreendedorismo: transformando idéias em negócios. Rio de Janeiro: Elsevier, 2008. 
DORNELAS, J. C. A. Empreendedorismo: transformando idéias em negócios. São Paulo: Empreende/Atlas, 2017.

FERREIRA, F.N., ROMEIRO FILHO, E. Fast fashion model product development system: a case study in a brazilian shirt manufacturing.Product, v. 7, n. 2, p. 134-139, 2019. http://dx.doi.org/10.4322/pmd.2019.016.

LACRUZ, A. J. Plano de negócios passo a passo: transformando sonhos em negócios. Rio de Janeiro: Qualitymark, 2008.

LONGENECKER, J. G.; MOORE, C. W.; PETTY, J. W.; PALICH, L. Administração de pequenas empresas. São Paulo: Cengage Learning, 2011.

LOPES, H. P. Censura das cópias na indústria da moda. dObra[s] - revista da Associação Brasileira de Estudos de Pesquisas em Moda, v. 12, n. 25, p. 111-128, abr. 2019.

MAXIMIANO, A. C. A. Administração para empreendedores. São Paulo: Pearson Prentice Hall, 2011

ROSA, C. A. Como elaborar um plano de negócios. Brasília: SEBRAE, 2013.

SERVIÇO BRASILEIRO DE APOIO ÀS MICROS E PEQUENAS EMPRESAS. Sobrevivência das empresas no Brasil. Brasília: SEBRAE, 2016.

THIOLLENT, M. Metodologia da pesquisa-ação. 15 ed. São Paulo: Cortez, 2007.

THIOLLENT, M. O Processo de entrevista. In: THIOLLENT, M. Crítica metodológica, investigação social e enquete operária. São Paulo: Polis, 1985.

YIN, R. K. Estudo de caso: planejamento e métodos. 2. ed. Porto Alegre: Bookman, 2001. 